\title{
Antagonistic effects of RAC1 and tumor-related RAC1b on NIS expression in thyroid
}

\author{
Márcia Faria1,2,3, Daniela Félix,4, Rita Domingues ${ }^{1,4}$, Maria João Bugalho1,5, Paulo Matos 2,3 and Ana Luísa Silva1,4 \\ 'Serviço de Endocrinologia, Diabetes e Metabolismo do Centro Hospitalar Universitário de Lisboa Norte-Hospital Santa Maria, Lisboa, Portugal \\ 2BioISI - Biosystems and Integrative Sciences Institute, Faculdade de Ciências da Universidade de Lisboa, Lisboa, Portugal \\ 3Departamento de Genética Humana, Instituto Nacional de Saúde Doutor Ricardo Jorge, Lisboa, Portugal \\ 4ISAMB - Instituto de Saúde Ambiental, Faculdade de Medicina da Universidade de Lisboa, Lisboa, Portugal \\ ${ }^{5}$ Faculdade de Medicina da Universidade de Lisboa, Lisboa, Portugal
}

Correspondence should be addressed to A L Silva: silva.r.analuisa@gmail.com

\begin{abstract}
Thyroid cancer (TC) is the most common endocrine malignancy. The sodium-iodide symporter (NIS), responsible for active transport of iodide into thyroid cells, allows the use of radioactive iodine (RAI) as the systemic treatment of choice for TC metastatic disease. Still, patients with advanced forms of TC often lose the ability to respond to RAI therapy, which results in worse survival rates. We have shown that the overexpression of RAC1b, a tumor-related RAC1 splice variant, is associated with less favorable clinical outcomes in differentiated TCs derived from the follicular epithelial (DTCS). RAC1b overexpression is also significantly associated with the presence of MAPK-activating BRAFV600E mutation, which has been previously implicated in the loss of NIS expression. Here, we show that increased RAC1b levels are associated with NIS downregulation in DTCs and demonstrate that ectopic overexpression of RAC1b in non-transformed thyroid cells is sufficient to decrease TSH-induced NIS expression, antagonizing the positive effect of the canonically spliced RAC1 GTPase. Moreover, we clearly document for the first time in thyroid cells that both NIS expression and iodide uptake are hampered by RAC1 inhibition, highlighting the role of RAC1 in promoting TSH-induced NIS expression. Our findings support a role for RAC1 and RAC1 $1 \mathrm{~b}$ signaling in the regulation of NIS expression in thyroid cells and suggest that RAC1b in cooperation with other cancer-associated signaling cues may be implicated in the response of DTCs to RAI therapy.
\end{abstract}

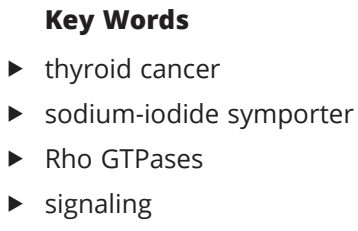

Key Words

- Rho GTPases

- signaling

\section{Introduction}

Thyroid cancer (TC) is the most common endocrine malignancy and its incidence has increased worldwide over the last few decades (Pellegriti et al. 2013). The follicular cell-derived, well-differentiated thyroid carcinomas (DTC) represent the most frequent forms of thyroid cancer and are classified into follicular thyroid cancer (FTC) and papillary thyroid cancer (PTC), the latter accounting for $80 \%$ of all cases (Dralle et al. 2015). Follicular cell-derived neoplasms arise from the follicular cells in thyroid gland, which are responsible for production and secretion of iodine-containing thyroid hormones (Dralle et al. 2015).

The active transport of iodide across the plasma membrane into thyroid follicles is mediated by the sodium-iodide symporter (NIS), an intrinsic plasma membrane protein found at the basolateral membrane of thyroid follicular cells. It belongs to the human solute 
carrier (SLC) family of transporters and uptakes iodide through the co-transport of two $\mathrm{Na}^{+}$and one I- from the bloodstream, using the $\mathrm{Na}^{+}$gradient maintained by the $\mathrm{Na}^{+} / \mathrm{K}^{+}$ATPase (Dohán et al. 2003). NIS is highly expressed in thyroid follicles and is a key contributor to thyroid hormone synthesis (Dohán \& Carrasco 2003). The majority (68-86\%) of DTCs retain the functional expression of NIS (Castro et al. 2001, Wapnir et al. 2003), which enables the use of radioactive iodine (RAI) as a diagnostic and therapeutic tool, to monitor and eliminate remaining tumor cells and metastases after total thyroidectomy. In fact, RAI therapy is the initial systemic treatment of choice for non-refractory metastatic DTC. Still, about 30\% of these patients lose the ability to respond to RAI therapy (refractory-thyroid cancer), which drastically reduces their survival rates (Cooper et al. 2006), since no effective alternative therapies are available. Defective functional NIS expression is considered the main reason for impaired iodide uptake in refractory-thyroid cancer (Durante et al. 2006, Spitzweg et al. 2014).

The primary regulator of NIS expression in thyroid gland is the thyroid-stimulating hormone (TSH) (Kogai et al. 1997, Ravera et al. 2017), acting through several pathways that respond to the accumulation of cyclic adenosine monophosphate (cAMP). One well-established pathway leads to the binding of the Pax8 transcription factor to an upstream enhancer element on the NIS gene promoter (NUE), a primary requirement for the full activation of NIS expression (Taki et al. 2002, Kogai $\&$ Brent 2012). Stimulation of p38 mitogenic kinase activity was also shown to be critical for TSH-induced NIS expression in thyroid cells (Pomerance et al. 2000). In breast cancer cells, induction of p38 kinase activity was also implicated in NIS expression enhancement, involving the activity of the small GTPase RAC1 (Kogai et al. 2012). RAC1 is a member of the RAS superfamily of small GTP-binding proteins, comprising a class of molecular 'switches' that regulate signaling pathways involved in processes such as gene expression, cell proliferation and cell migration (Heasman \& Ridley 2008). An alternative splicing event leads to the generation of RAC1b, a fast activating splice variant of RAC1 (Matos et al. 2003, Fiegen et al. 2004), shown to be overexpressed in several tumor types, namely breast, colon, pancreatic, lung and thyroid cancers (Schnelzer et al. 2000, Matos et al. 2008, Stallings-Mann et al. 2012, Zhou et al. 2013, Silva et al. 2013, Mehner et al. 2015, Faria et al. 2016). RAC1b results from the inclusion of an additional exon (exon $3 b$ ), which confer to this splice isoform important pro-tumorigenic properties (Jordan et al. 1999, Melzer et al. 2019). RAC1b lacks downregulation by the regulatory factor Rho-GDI, existing predominantly in the plasma membrane, in a favorable position to become activated (Matos et al. 2003, Matos \& Jordan 2005). However, compared to RAC1, RAC1b shows selective downstream signaling, favoring specific pathways such as the production of reactive oxygen species, NF- $\mathrm{kB}$ activation and epithelialmesenchymal transition (Matos et al. 2003, Matos \& Jordan 2005, 2006, Radisky et al. 2005, Faria et al. 2017). RAC1 and RAC1b may also act in an antagonistic fashion in the regulation of specific cellular responses. In fact, its inability to bind RhoGDI makes RAC1b more available to activating upstream signals, competing with RAC1 and downregulating its activation (Matos et al. 2003, Matos \& Jordan 2006), thus behaving as an endogenous inhibitor of RAC1 pathways where RAC1b does not participate (Melzer et al. 2019).

We have previously shown that the overexpression of tumor-related RAC1b in follicular cell-derived thyroid carcinomas is associated with worse clinical outcomes (Silva et al. 2013, Faria et al. 2016). Particularly in the PTC subtype, overexpression of RAC1b was significantly associated with the oncogenic MAPK-activating BRAFV600E mutation (Silva et al. 2013), which in turn was related to the loss of NIS expression (Romei et al. 2008, Espadinha et al. 2009). This led us to hypothesize that RAC1b overexpression may also be implicated in NIS downregulation observed in DTCs.

With the present study, we intended to clarify whether RAC1 and RAC1b signaling would have an impact on NIS expression. We observed that the expression of NIS was negatively correlated with RAC1b overexpression in thyroid tumors. By using a RAC1/RAC1b expression model system in thyroid cell lines, we revealed antagonistic effects of RAC1 and RAC1b on NIS transcriptional regulation.

\section{Materials and methods}

\section{Cell lines and culture conditions}

The PCCL3 (BCRJ 0204) and the FRTL5 (ECACC 91030711) cell lines, derived from Fischer rat's thyroid follicular normal epithelium, were maintained in Coon's F-12 modified liquid medium (Merck) supplemented with $5 \%$ fetal bovine serum (FBS) (Gibco), $10 \mu \mathrm{g} / \mathrm{mL}$ of insulin (Sigma-Aldrich), $5 \mu \mathrm{g} / \mathrm{mL}$ of Apo-Transferrin (Apo-T) (Sigma-Aldrich) and $0.1 \mathrm{mU} / \mathrm{mL}$ of TSH (Sigma-Aldrich). 
When appropriate, cells were cultured in starvation medium (F12 Coon's Modification medium supplemented with $0.2 \%(\mathrm{v} / \mathrm{v}) \mathrm{FBS}$ and $5 \mu \mathrm{g} / \mathrm{mL}$ of Apo-T) or stimulation medium (F12 Coon's Modification medium supplemented with $5 \%(\mathrm{v} / \mathrm{v})$ FBS, $5 \mu \mathrm{g} / \mathrm{mL}$ of Apo-T and $1 \mathrm{mU} / \mathrm{mL}$ of TSH). Y-PCCL3 cells were generated from parental PCCL3 cells through stable transfection of the pcDNA-HS-YFPhygro construct (coding the halide-sensitive yellow fluorescent protein HS-YFP- F46L/H148Q/I152L). Cells were cultured in parental PCCL3 medium supplemented with hygromycin B (Santa Cruz) selective agent. The human PTC-derived cell line BCPAP (RRID:CVCL_0153) was maintained in RPMI 1640 (Gibco) with 10\% FBS. Cells were maintained at $37^{\circ} \mathrm{C}$ in a $5 \%$ humidified $\mathrm{CO}_{2}$ environment and discarded after 20 passages.

Treatment of cells with the RAC1 selective inhibitors NSC23766 $(100 \mu \mathrm{M}$, Santa Cruz) or EHT1864 $(50 \mu \mathrm{M}$, Santa Cruz) was performed for $4 \mathrm{~h}$ in the appropriate supplemented medium. Treatment of BCPAP cells with the MEK-inhibitor AZD-6244 $(10 \mu \mathrm{M}$, APExBio $)$ was performed for $48 \mathrm{~h}$ in RPMI 1640 medium.

\section{Plasmid constructs and transfections}

The plasmids pEGFP-RAC1b, pEGFP-RAC1 and pEGFPG12V-RAC1 (Barros et al. 2009) were a kind gift from Dr Peter Jordan from Instituto Nacional de Saúde Dr. Ricardo Jorge. The pEGFP-C3 (BD Biosciences Clontech) was used for mock controls.

Transfections were carried out using Lipofectamine 2000 (Invitrogen), according to the manufacturer's instructions. Cells seeded in six-well plates at $70-80 \%$ confluence were transfected with $2 \mu \mathrm{g}$ of total plasmid DNA. The amounts used of RAC1/RAC1b constructs were optimized to achieve similar levels of protein expression (when required, the total amount of DNA was adjusted with empty vector).

For the transfection of PCCL3 and FRTL5 cell lines, cells were subjected to serum starvation in the absence of TSH (starvation medium) for $24 \mathrm{~h}$ prior to transfection. Cells were transfected in stimulation medium and subjected to TSH stimulation for $24 \mathrm{~h}$. Cells were then harvested for RNA or protein expression assays.

\section{RNA extraction and cDNA synthesis}

Total RNA was obtained from cultured cells using the ready-to-use reagent TripleXtractor (GRiSP Research Solutions) according to the manufacturer's instructions.
cDNA was synthetized from $2 \mu \mathrm{g}$ of RNA using random primers (Roche) and RevertAid Reverse Transcriptase (Thermo Scientific), following the manufacturer's protocol. Archival tumoral RNA samples, collected in accordance with protocols approved by the institutional ethical review board (Silva et al. 2013, Faria et al. 2016), had been previously subjected to cDNA synthesis and accessed for RAC1/RAC1b expression (Silva et al. 2013, Faria et al. 2016).

\section{RT-qPCR}

NIS expression levels were quantified by SYBR Greenbased quantitative reverse transcription polymerase chain reaction (RT-qPCR) on Light Cycler 480II (Roche), using Xpert Fast SYBR (Grisp) and following manufacturer's instructions. Fold difference in mRNA expression was calculated using efficiency corrected model of $2^{-\Delta \Delta C t}$ method (Pfaffl 2001). HPRT1 and TBP were used as endogenous control genes for rat and human, respectively. NIS levels were normalized to endogenous control expression level. NIS normalized values were then expressed relative to those of a reference sample (pool of TSH-stimulated rat cell lines or pool of normal human thyroid tissues, for rat and human NIS assessment, respectively). Expression values correspond to arbitrary units representing fold differences relative to the reference sample.

Primers used were the following: NIS RAT F ( 5 '-AAGTG ACCGGGTTGGACATC) and NIS RAT R (5'-CCTTCATACCA CCCACGGTAG); NIS human F (5'-CCTGCTAACGACTCC AGCA) and NIS human R (5'-CCAGGGCACCGTAATAGA GA); HPRT1 F (5'-GCTGAAGATTTGGAAAAGGTG) and HPRT1 R (5'-AATCCAGCAGGTCAGCAAAG) and TBP F (5'-TGCACAGGAGCCAAGAGTGAA) and TBP R (5'-CA CATCACAGCTCCCCACCA).

\section{Total protein lysates and Western blot}

Protein extracts were prepared from transfected cultured cells in Laemmli sample buffer (supplemented with $1 \mathrm{U} / \mu \mathrm{l}$ Benzonase, Sigma-Aldrich).

Protein lysates were resolved, according to standard protocols, in $12 \%$ SDS-PAGE and transferred to PVDF membranes (Bio-Rad). The primary antibody mouse monoclonal anti-RAC1 (Millipore, 05-389) was used in Western blot at 1:2000. The primary antibody mouse monoclonal anti-p38 (BD Biosciences, 612168) was used in Western blot at 1:1000, while the anti-phospho-p38 antibody (BD Biosciences, 612565) was used at 1:750. Detection was carried out using secondary 
peroxidase-conjugated anti-mouse IgG (Bio-Rad) antibody followed by chemiluminescence.

\section{Active RAC pull-down assays}

PCCL3 and FRTL5 cells were seeded in $35 \mathrm{~mm}$ dishes. After specific experimental conditions applied to each cell line, cells were washed in cold PBS and lysed on ice in $250 \mu \mathrm{L}$ of lysis buffer (50 mM Tris- $\mathrm{HCl}$ (pH 7.5), $100 \mathrm{mM}$ $\mathrm{NaCl}, 1 \%[\mathrm{v} / \mathrm{v}]$ Nonidet P-40 (NP-40), 10\% [v/v] glycerol, $10 \mathrm{mM} \mathrm{MgCl}$, and a protease inhibitor cocktail (SigmaAldrich)). The PAK-CRIB-domain pull-down assay was performed as described previously (Matos et al. 2003). Briefly, total lysates were cleared by centrifugation at 2600 $\boldsymbol{g}$ for $5 \mathrm{~min}$ and an aliquot of $40 \mu \mathrm{L}$ representing 'Total Lysate' was solubilized in Laemmli sample buffer. The remaining lysate (approximately $200 \mu \mathrm{L}$ ) was incubated for $1 \mathrm{~h}$ at $4^{\circ} \mathrm{C}$ with a CRIB-domain peptide pre-coupled to streptavidin-agarose beads. Beads were washed three times with lysis buffer and the precipitated protein complexes were solubilized in Laemmli sample buffer. Samples were analyzed by Western blot.

\section{HS-YFP-based iodide influx assay}

Iodide influx was accessed in Y-PCCL3 cells stably expressing the halide-sensitive yellow fluorescent protein (HS-YFP-F46L/H148Q/I152L) (Rhoden et al. 2007, 2008). Y-PCCL3 were plated in eight-well chamber slides (ibidi). After $24 \mathrm{~h}$, the culture medium was replaced, cells were serum-starved for $24 \mathrm{~h}$ and subsequently stimulated for 96 $\mathrm{h}$ with $1 \mathrm{mU} / \mathrm{mL}$ TSH. When appropriate, cells were treated with EHT1864 $(50 \mu \mathrm{M}, 4 \mathrm{~h})$. Cells were then washed and incubated for $15 \mathrm{~min}$ at $37^{\circ} \mathrm{C}$ with influx-solution $(137 \mathrm{mM}$ $\mathrm{NaCl}, 2.7 \mathrm{mM} \mathrm{KCl}, 0.7 \mathrm{mM} \mathrm{CaCl}_{2}, 1.1 \mathrm{mM} \mathrm{MgCl}_{2}, 1.5 \mathrm{mM}$ $\mathrm{KH}_{2} \mathrm{PO}_{4}, 8.1 \mathrm{mM} \mathrm{Na}_{2} \mathrm{HPO}_{4}$, and $10 \mathrm{mM}$ glucose, $\mathrm{pH}$ 7.4) and transferred to the confocal microscope. PBS containing $1 \mathrm{mM} \mathrm{NaI}$ was then added to cells and the decay of YFP fluorescence was followed by live imaging microscopy for $600 \mathrm{~s}$, acquiring an image every $10 \mathrm{~s}$. To confirm that the iodine influx observed was specifically mediated by NIS, additional assays were performed in the presence of TSH and $\mathrm{ClO}_{4}^{-}$, a competitive inhibitor of iodide uptake by NIS: cells were incubated with $1 \mathrm{mM} \mathrm{ClO}_{4}^{-}$, for $10 \mathrm{~min}$, before PBS$\mathrm{NaI}$ solution was added. Images were stacked and analyzed with Image J, defining whole field regions of interest (ROIs) for pixel intensity measurements that excluded saturated cells. Fluorescence decay data were fitted to exponential decay curves and the Iodide influx rate constants calculated using GraphPad Prism statistical software.

\section{Databases, bioinformatic tools and statistical analysis}

We used the TSVdb tool (Sun et al. 2018) to collect NIS and RAC1/RAC1b isoform expression and clinical information from The Cancer Genome Atlas project (TCGA) RNA-Seq data. The dataset was composed by 501 primary PTC and 59 normal thyroid tissue samples (Thyroid Carcinoma (THCA) project). NIS and RAC1/RAC1b expression data were retrieved from TSVdb in the RSEM format (Li \& Dewey 2011). Tumor and TCGA expression data were analyzed using non-parametric statistical tests (Spearman's correlation coefficient and Mann-Whitney's $U$ test, when appropriate). Statistical analysis was carried out using GraphPad Prism statistical software. When appropriate, values are displayed in either box plots (median, IQR and whiskers from minimum to maximum), scatter plots, or bar chats, as mean \pm S.D. Statistical comparisons of rates and proportions were made using unpaired two-tailed Student's $t$-test. Statistical significance was considered at $P \leq 0.05$.

\section{Results}

To test whether RAC1b has a role in the modulation of NIS expression, we started by accessing NIS transcript levels in a group of 64 archival RNA samples obtained from follicular cell-derived thyroid tumors (comprising both PTC and FTC subtypes), in which RAC1b levels had been previously determined (Silva et al. 2013, Faria et al. 2016). RAC1b-overexpressing tumors had been defined (Silva et al. 2013, Faria et al. 2016) as those with expression levels above a threshold corresponding to the mean value plus two S.D. of RAC1b expression level in a normal thyroid group. NIS expression was assessed by quantitative RT-PCR. By comparing tumors presenting RAC1b overexpression $(n=32)$ to those that did not $(n=32)$, we found that samples negative for RAC1b expression presented higher levels of NIS than RAC1b-overexpressing samples $(P=0.0421$, nonparametric Mann-Whitney's $U$ test; Fig. 1A). Also, an inverse correlation between RAC1b and NIS expression levels was observed $(P=0.0035$, Spearman's correlation coefficient, $r S=-0.3344$; Fig. 1B). NIS expression levels were also found to be higher in the RAC1b-overexpressing subgroups when performing the independent analysis of PTC $(n=41 ; P=0.0147$, nonparametric Mann-Whitney's $U$ test; Fig. 1C) and FTC $(n=23)$ samples, although statistical significance was not reached for the FTC subtype $(P=0.2489$, nonparametric Mann-Whitney's $U$ test; Fig. 1D). These results suggest that RAC1b may have a role in NIS downregulation in thyroid 

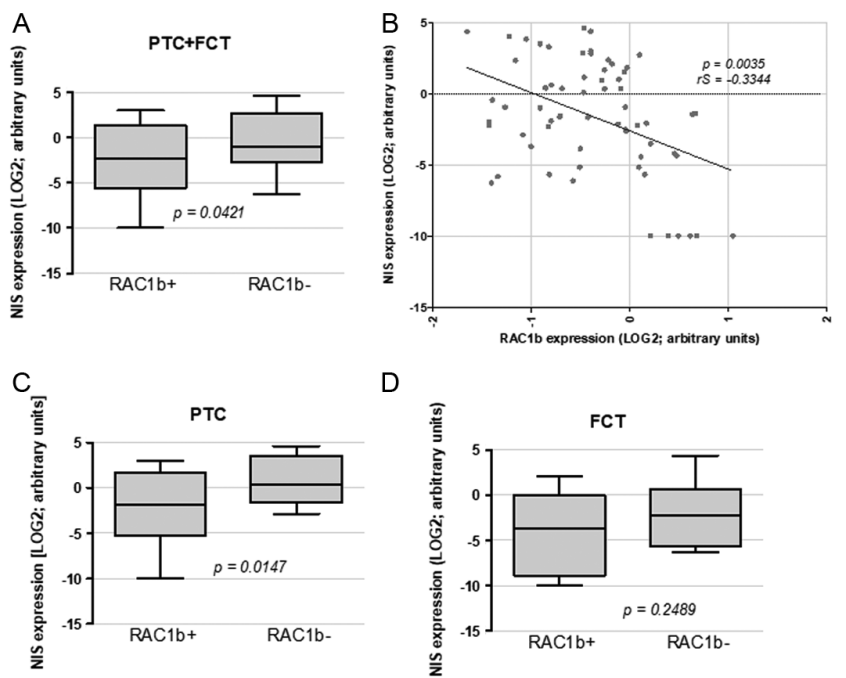

D
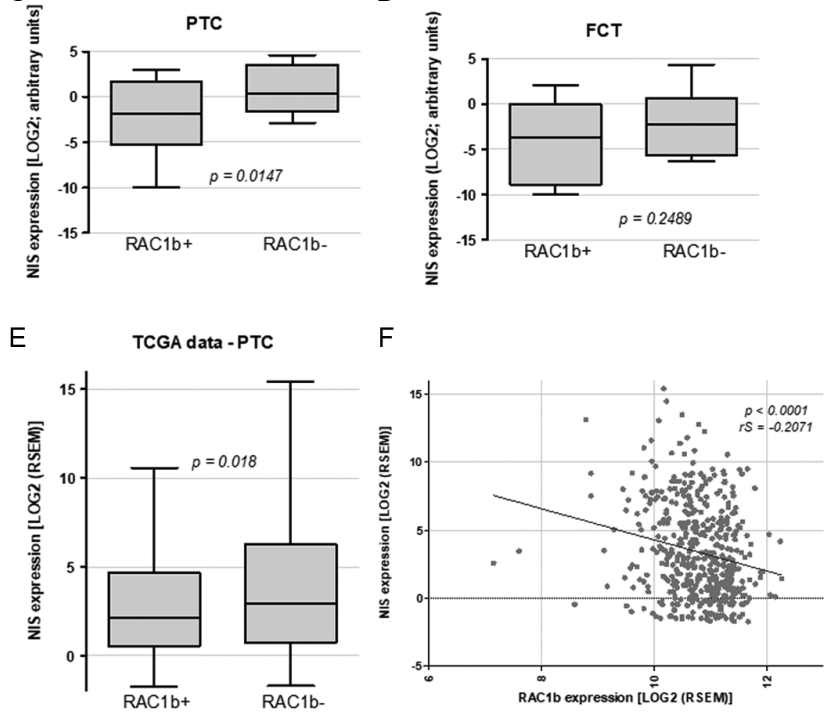

\section{Figure 1}

NIS expression levels in RAC1b-positive and RAC1b-negative thyroid follicular cell-derived carcinomas. (A, B, C and D) NIS expression levels quantified by RT-qPCR correspond to arbitrary units representing fold differences relative to a reference sample and corrected to TBP levels, used as endogenous control gene. NIS levels were assessed in a set of archival mRNA samples of follicular cell-derived, well-differentiated thyroid carcinomas $(n=64)$, comprising both PTC $(n=41)$ and FTC $(n=23)$ subtypes, for which RAC1b expression levels have been previously characterized (Silva et al. 2013, Faria et al. 2016). (A, C and D) Results are depicted as boxplots, with whiskers from minimum to maximum, of the LOG2 value measured for each sample, comparing RAC1b-overexpressing $(n=32)$ and non-overexpressing $(n=32)$ subsets. Comparisons were made using a one-tailed Mann-Whitney's $U$ test. (B) Scatter plot of RAC1b versus NIS expression levels. Spearman's correlation coefficient between the two data series and its respective $P$ value are shown in the upper right corner. (E and F) Analysis of RAC1/RAC1b and NIS expression based on RNA-Seq data (comprising 501 primary PTCs) retrieved from The Cancer Genome Atlas project (TCGA) database. (E) Boxplots, with whiskers from minimum to maximum, of the NIS expression levels expressed as LOG2 of RSEM format values (Li \& Dewey 2011) retrieved from TCGA using the TSVdb tool (Sun et al. 2018). NIS expression levels were compared between RAC1b-overexpressing and RAC1b-non-overexpressing PTCs (RAC1b overexpression was defined as described in Silva et al. 2013, Faria et al. 2016). The significance of the differences between the two datasets was calculated using Mann-Whitney's $U$ test, assuming a significance level of $\alpha=0.05$. (F) Scatter plot of RAC1 b versus NIS expression levels in the TCGA PTC cohort. Spearman's correlation coefficient between the two data sets and its respective $P$ value are shown in the upper right corner. cancers. We thus performed a complementary analysis using RAC1/RAC1b and NIS expression data retrieved from TCGA database (comprising 501 primary PTC and 59 normal thyroid tissue samples - Supplementary Fig. 1, see section on supplementary data given at the end of this article). RAC1b-overexpressing tumors were defined as described (Silva et al. 2013, Faria et al. 2016) and NIS expression levels were compared between RAC1b-overexpressing and RAC1b-non-overexpressing PTCs (Fig. 1E). Consistent with the results observed in our DTC series, NIS expression in the TCGA cohort was lower in the RAC1b-overexpressing subgroup $(P=0.018$ nonparametric Mann-Whitney's $U$ test; Fig. 1E), and the inverse correlation between NIS and RAC1b levels was also clearly present $(P<0.0001$, Spearman's correlation coefficient, $\mathrm{rS}=-0.2017$; Fig. 1F).

Taken together, these observations led us to hypothesize that if RAC1 signaling also stimulates NIS expression in thyroid systems - similar to that described in breast cancer cells (Kogai et al. 2012) - the overexpression of the antagonist variant RAC1b could constitute a new mechanism contributing to NIS downregulation in thyroid tumors.

To further investigate this hypothesis, we started by first determining whether, similarly to what was described in colorectal cells (Matos et al. 2003, Matos \& Jordan 2005), the presence of RAC1b could also downregulate RAC1 activity in thyroid cells. For this, we used the nonneoplastic rat thyroid follicular cell line PCCL3, a widely established model of TSH-responsive, NIS expressing cells (Trapasso et al. 1999, Kogai \& Brent 2009, Dumont et al. 2016). Cells were first stimulated with TSH and then either mock-transfected or transfected with GFP-tagged RAC1b (wild-type) and then analyzed by the PAK1 CRIB domain pull-down assay, which evaluates the amount of active, GTP-bound RAC1 present in lysates from these cells (Matos et al. 2003). We observed that stimulation of PCCL3 cells with TSH increased the levels of intracellular GTP-bound (active) RAC1 and that the overexpression of RAC1b completely prevented this activation (Fig. 1A). We next addressed the question of whether RAC1 could, by itself, modulate NIS transcript levels in thyroid cells. For that we transfected PCCL3 cells, in the presence of $\mathrm{TSH}$, with either RAC1 or RAC1b (wild-type) isoforms, or the constitutively active RAC1 mutant (G12V-RAC1). Consistently with a role for active RAC1 signaling in the regulation of NIS expression, we observed that the 
A

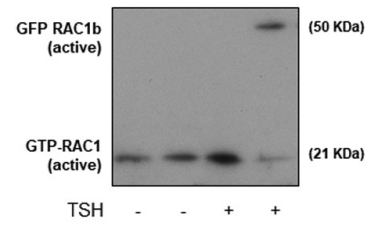

B
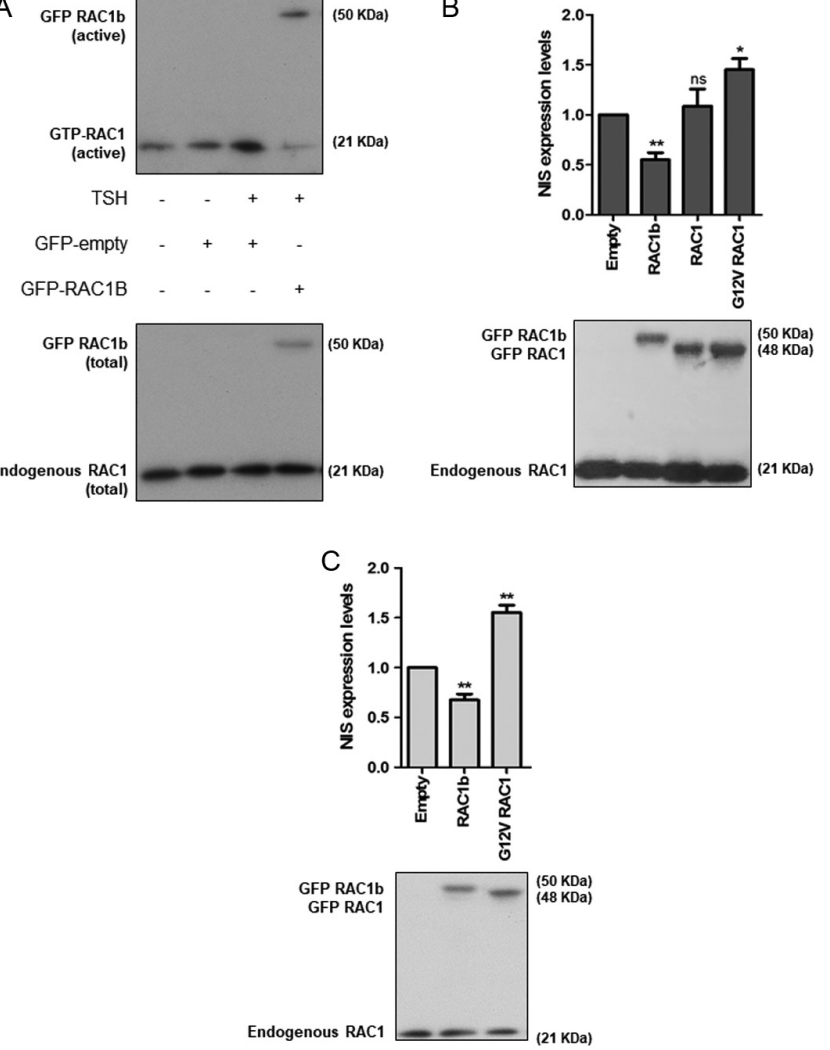

Figure 2

Effects of RAC1 and RAC1b on NIS transcriptional expression in nonneoplastic, TSH-responsive thyroid follicular cell lines. (A) The PCCL3 cell line was transiently transfected with GPF-empty and GFP-RAC1b, either in the presence or absence of TSH. Endogenous RAC1 levels were assessed by Western Blot using anti-RAC1 primary antibody which detects both RAC1 and RAC1b variants (lower panel). The active GTP-bound fraction of RAC1 was isolated using the PAK-CRIB domain pull-down assay (upper panel) and monitored by Western Blot using anti-RAC1 primary antibody. (B and C) FRLT5 and PCCL3 cells were transiently transfected with GPF-empty, GFP-RAC1b, GFP-RAC1 or GFP-G12V RAC1 expressing constructs, upon TSH stimulation (1 $\mathrm{mU} / \mathrm{mL}$ ). The ectopic expression of RAC1b and RAC1 variants was monitored by Western Blot. RAC1/1b expression was assessed using anti-RAC1 primary antibody. NIS mRNA levels were assessed by RT-qPCR and correspond to arbitrary units representing fold differences relative to a reference sample, corrected to HPRT levels used as endogenous control gene. Plotted values are the mean \pm s.D. (error bars) of three independent assays, compared with the set of samples transfected with GFP-empty vector (Empty). Comparisons to control (Empty) were made using a two-tailed Student's $t$-test. $* P \leq 0.05 * * P \leq 0.01$

overexpression of constitutively active G12V-RAC1 could significantly increase the abundance of endogenous NIS transcript in these cells, even in the presence of TSH stimulus (Fig. 2B). Moreover, we also confirmed that the overexpression of RAC1b had the exact opposite effect, significantly decreasing NIS transcript levels (Fig. 2B). To ascertain that these were not effects exclusively seen in the PCCL3 model, we repeated these experiments in the also well-established FRTL5 model, another TSH stimulation-responsive, non-transformed Rat thyroid cell line (Kogai et al. 1997, Kogai \& Brent 2009), and observed equivalent responses (Fig. 2C).

To further confirm RAC1's impact on the modulation of TSH-induced NIS expression, we inhibited endogenous RAC1 activity using the selective inhibitors NSC23766 and EHT1864. A significant decrease in NIS transcription levels was observed following treatment with NSC23766 or EHT1864 in the PCCL3 and FRTL5 cell lines, again consistent with RAC1 being a positive regulator of NIS transcriptional activation within the TSH-mediated response. (Fig. 3A). The efficacy of inhibiting endogenous RAC1 activation by NSC23766 and EHT1864 was confirmed using the PAK1 CRIB domain pull-down assay. This showed that either NSC23766 or EHT1864 treatment produced a substantial decrease in the active pool of endogenous RAC1 molecules in both FRTL5 and PCCL3 cells (Fig. 3B and C). In addition, the impact of TSH treatment on endogenous RAC1 activation was again addressed, comparing PCCL3 and FRTL5 cells. An increase in the GTP-bound fraction of endogenous RAC1 was observed upon TSH treatment, which was more evident in the PCCL3 cell line in agreement with the higher induction of NIS expression (Fig. 3D). Combined, these findings indicate that TSH-induced NIS expression in thyroid cells involves the stimulation of RAC1 activity.

P38-MAPK activation was shown to participate in the upregulation of NIS expression in thyroid context (Pomerance et al. 2000). Since the activation of RAC1 signaling has been reported to elicit p38 activity in breast cancer cells (Kogai et al. 2012), we investigated whether $\mathrm{p} 38$ could also be mediating the transcriptional upregulation of NIS downstream of RAC1 activation in thyroid cells. However, this does not seem to be the case since neither RAC1, RAC1b nor G12V-RAC1 ectopic overexpression produced a noticeable increase in p38-MAPK activity in non-transformed thyroid cells (Fig. 4).

Next, we investigated if signaling derived from RAC1/RAC1b would also have an impact on iodide uptake. To address this question, we established an iodide influx assay in PCCL3 cells, modified to stably express the halide-sensitive yellow fluorescent protein (YFP) F46L/H148Q/I152L mutant (HS-YFP) (Galietta et al. 2001, Loureiro et al. 2015, Matos et al. 2018), which has been also validated in thyroid cells (Rhoden et al. 2007, 2008). The HS-YFP inside these modified PCCL3 cells (Y-PCCL3) is quenched by iodide, enabling rapid changes 


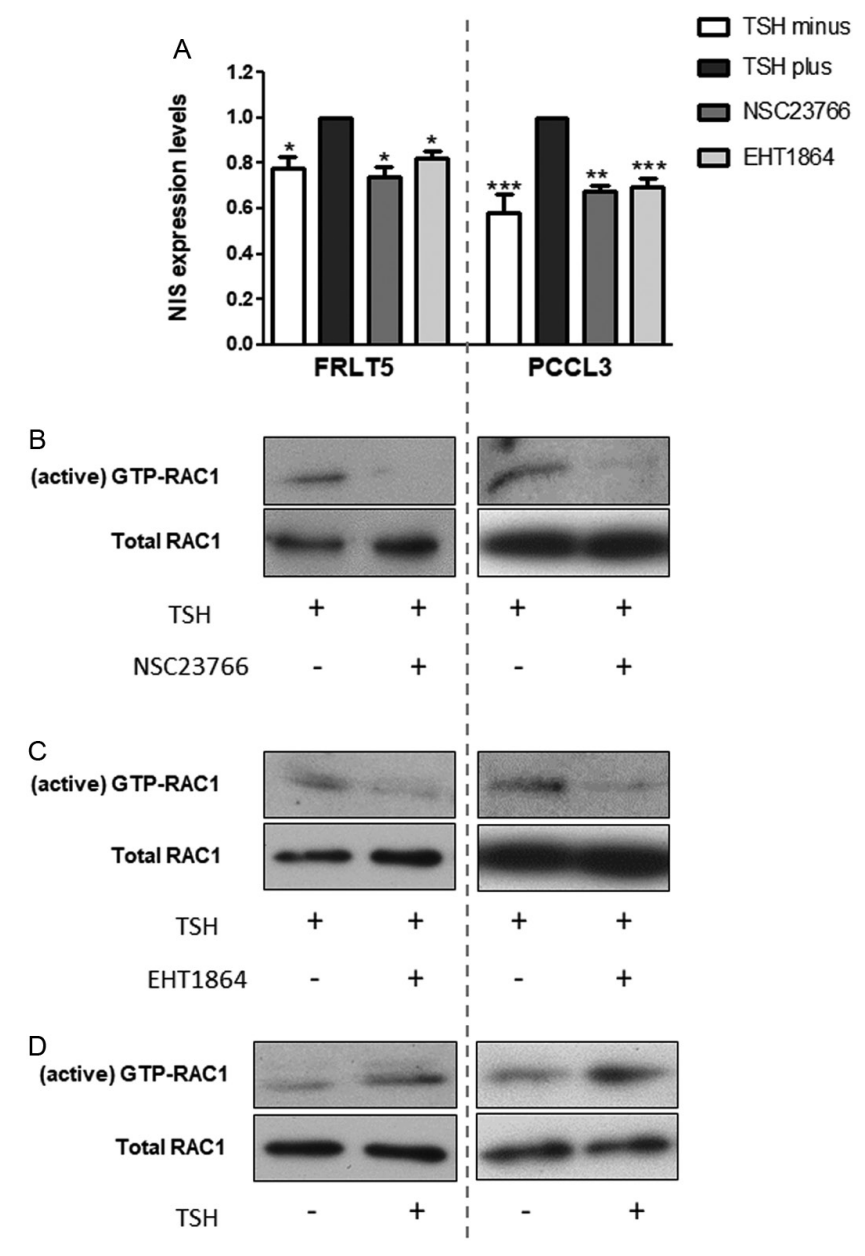

Figure 3

Impact of NSC23766- and EHT1864-mediated endogenous RAC1 inhibition on NIS transcriptional expression. FRTL5 and PCCL3 were subjected to a 24-h starvation period (TSH minus) followed by stimulation with TSH (1 $\mathrm{mU} / \mathrm{mL}$ for $24 \mathrm{~h}$; TSH plus), in the presence or absence of either NSC23766 (100 $\mu \mathrm{M}$ for $4 \mathrm{~h}$ ) or EHT1864 (50 $\mu \mathrm{M}$ for $4 \mathrm{~h}$ ). (A) Effect of NSC23766- and EHT1864-mediated endogenous RAC1 inhibition on NIS transcript levels. Levels of NIS mRNA quantified by RT-qPCR correspond to arbitrary units representing fold differences relative to a reference sample and corrected to HPRT levels used as endogenous control gene. Plotted values are the mean \pm S.D. (error bars) of three independent assays, compared with the group treated with only TSH (TSH plus). Comparisons were made using a two-tailed Student's $t$-test. $* P \leq 0.05 ; * * P \leq 0.01 ; * \star * P \leq 0.001$. Inhibition of endogenous RAC1 activation upon NSC23766 (B), EHT1864 (C) or TSH (D) treatment was assessed by monitoring the active GTP-bound fraction of RAC1 by PAK-CRIB domain pull-down assay. RAC1 levels were assessed by Western Blot using anti-RAC1 primary antibody.

in iodide intracellular concentration to be monitored in thyroid cells by live cell imaging. Y-PCCL3 cells were thus subjected to TSH stimulation in the presence and absence of EHT1864, NSC23766 or RAC1b ectopic overexpression. A considerably higher decay rate of HS-YFP fluorescence was observed upon TSH stimulation, compared to that detected in the absence of $\mathrm{TSH}$

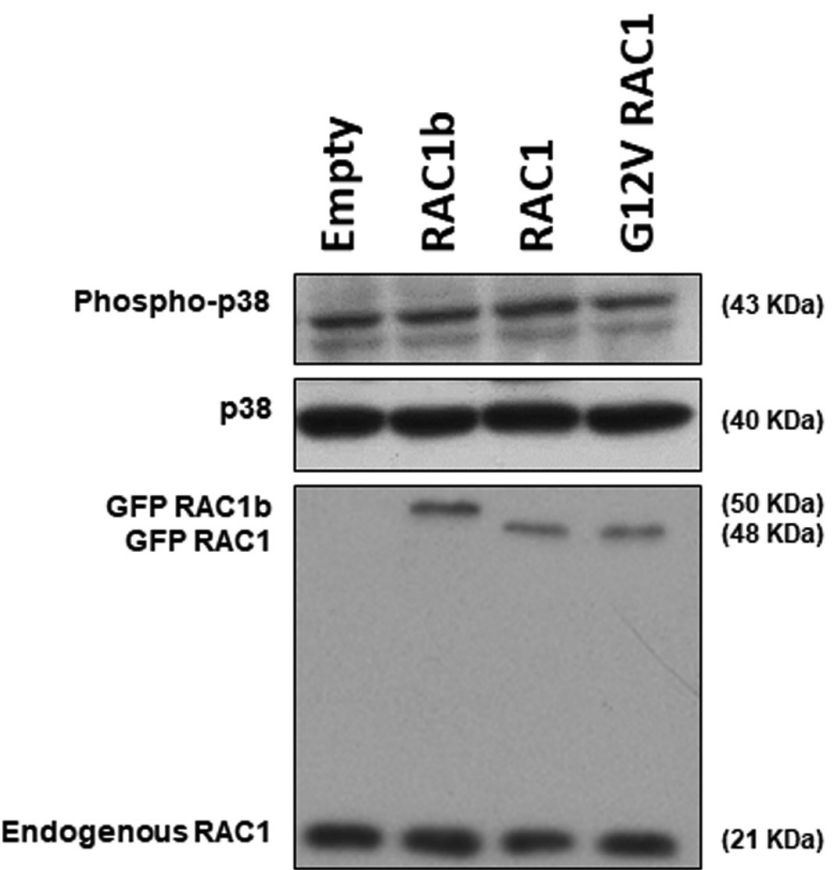

\section{Figure 4}

Impact of ectopic overexpression of RAC1 and RAC1b on p38-MAPK activation. Immunoblot showing p38-MAPK activation measured by assessing levels for phosphorylated and total p38-MAPK in protein lysates obtained from PCCL3 cells transiently transfected with GFP-RAC1b, GFP-RAC1 or GFP-G12V RAC1 constructs, upon TSH stimulation (1 mU/ $\mathrm{mL}$ ). The ectopic expression of RAC1b and RAC1 variants was monitored by Western Blot, using anti-RAC1 primary antibody which detects both RAC1 and RAC1b variants.

(Fig. 5). This is consistent with the enhancement of NIS expression induced by TSH that ultimately promotes NIS-mediated iodide uptake. We confirmed that the observed TSH-induced iodide influx was mediated by NIS since it was completely abolished in the presence of perchlorate $\left(\mathrm{ClO}_{4}^{-}\right)$, a competitive inhibitor of iodide uptake by NIS (Cianchetta et al. 2010). The TSH-induced iodide influx, however, was shown to be significantly reduced by both NSC23766 and EHT1864 treatment (Fig. 5), consistent with the observed downregulation of NIS expression observed upon endogenous RAC1 inhibition. A similar impairment of iodide influx was observed as a consequence of ectopic overexpression of RAC1b, again supporting antagonistic roles of RAC1 and RAC1b in the modulation of NIS functional expression.

Given that our results support a potential effect of RAC1 on enhancing NIS expression, we further addressed the impact of ectopic RAC1 overexpression on NIS transcription levels in a setting of thyroid malignancy. We used the human PTC derived cell line BCPAP, in which TSH-induced NIS expression is impaired. Consistent 


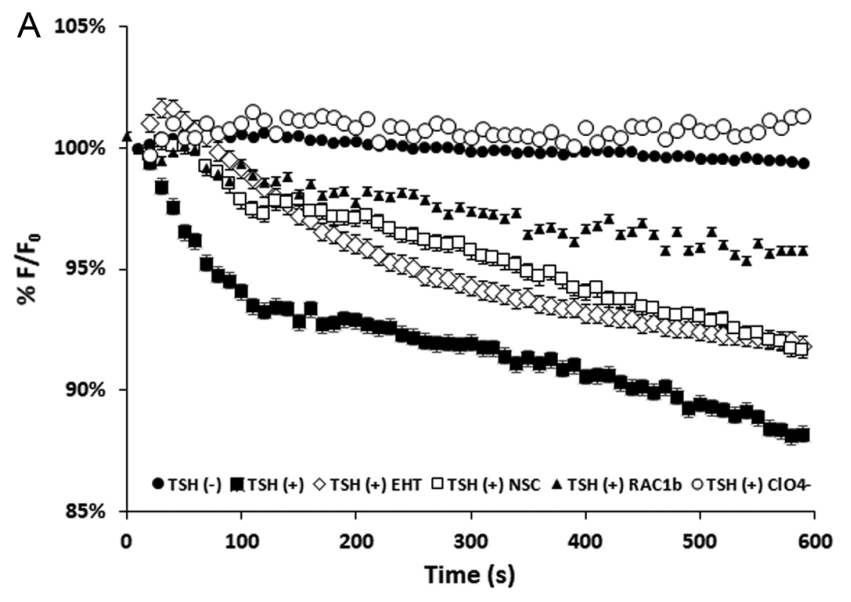

B

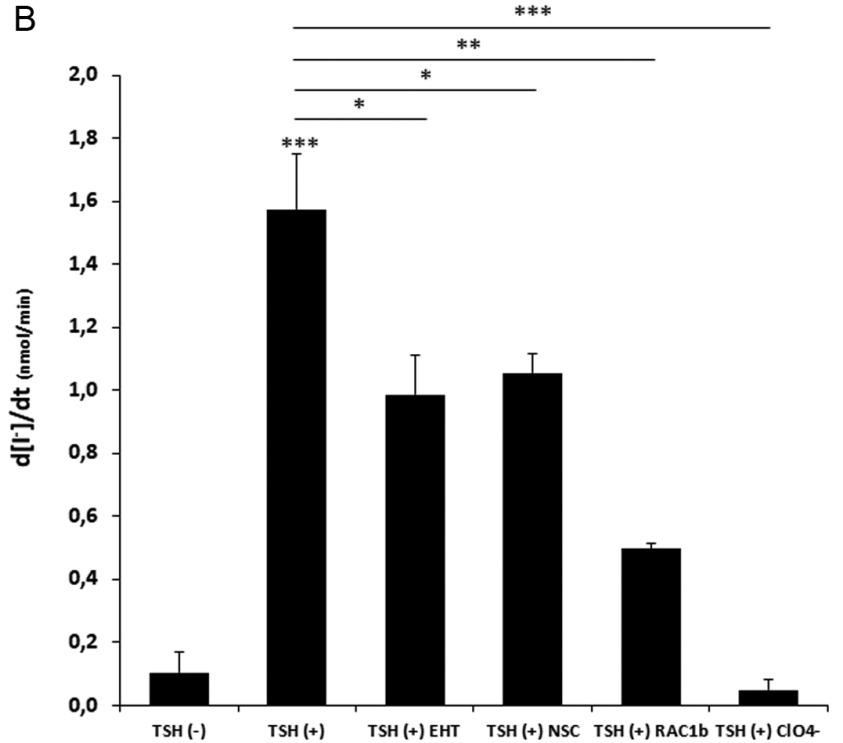

Figure 5

Effects of RAC1 selective inhibitors NSC23766 and EHT1864 on TSHinduced iodide uptake in PCCL3 cells. PCCL3 cells stably expressing the YFP-halide sensor were subjected to a 24-h starvation period (TSH minus) and then treated with TSH (1 mU/mL) for $96 \mathrm{~h}$ (TSH plus), in the presence or absence of either NSC23766 (100 $\mu \mathrm{M}$ for $4 \mathrm{~h}$ ) or EHT1864 (50 $\mu \mathrm{M}$ for 4 h). TSH-stimulated PCCL3 cells transfected with GFP-RAC1b-expressing construct were assessed also. (A) Fluorescence decay traces and (B) initial iodide influx rates. Iodide influx assays were performed both with or without TSH stimulation (TSH plus and TSH minus, respectively) and in the presence or absence of either NSC23766- or EHT1864-induced endogenous RAC1 inhibition. Additional assays were performed in the presence of both $\mathrm{TSH}$ and $\mathrm{ClO}_{4}{ }^{-}\left(1 \mathrm{mM}, 10 \mathrm{~min} ; \mathrm{ClO}_{4}^{-}\right)$, a competitive inhibitor of iodide uptake by NIS, and upon ectopic RAC1b overexpression (RAC1 b). YFP fluorescence was recorded continuously for $600 \mathrm{~s}$, acquiring an image every $10 \mathrm{~s}$, after exposure to $1 \mathrm{mM} \mathrm{Nal}$ (as described in Rhoden et al. 2007). Fluorescence (F) was plotted over time as percentage of fluorescence at time $0\left(F_{0}\right)$. lodide influx rates calculated by fitting the curves to the exponential decay function to derive the maximal slope that corresponds to initial influx of $\mathrm{I}$ - into the cells. Data are means \pm S.E.M. of three independent assays. Comparisons were made using a two-tailed Student's $t$-test. ${ }^{*} P \leq 0.05 ;{ }^{*} P \leq 0.01 ;{ }^{* \star *} P \leq 0.001$.

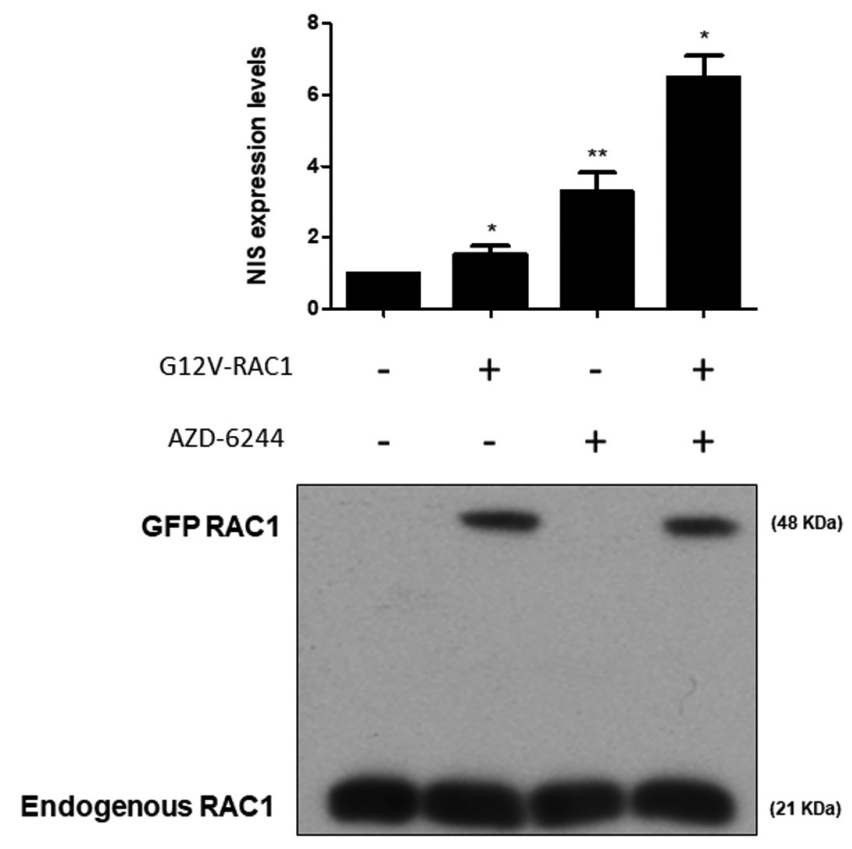

Figure 6

Effect of RAC1 on NIS transcriptional expression in a thyroid follicular cancer cell-derived line. The PTC-derived BCPAP cell line was transiently transfected with GFP-empty vector or GFP-G12V RAC1 expressing constructs, in the presence or absence of the MEK inhibitor AZD-6244 $(10 \mu \mathrm{M}$ for $48 \mathrm{~h})$. The impact of AZD-6244 treatment and ectopic overexpression of the constitutively active G12V RAC1 mutant on NIS transcript levels was addressed by RT-qPCR. NIS mRNA levels correspond to arbitrary units representing fold differences relative to a reference sample, corrected to TBP levels used as endogenous control gene. Plotted values are the mean \pm SD (error bars) of three independent assays, compared with the set of samples transfect with GFP-empty vector. The ectopic expression of the G12V RAC1 variant was monitored by Western Blot, using anti-RAC1 primary antibody. Comparisons were made using a two-tailed Student's $t$-test. $* P \leq 0.05 ; * \star P \leq 0.01$.

to that observed in the non-neoplastic cell models, overexpression of the constitutively active mutant G12V-RAC1 induced an increase in NIS transcript levels (Fig. 6) suggesting that RAC1 activation is able to enhance NIS expression even outside the context of TSH stimulation, namely in a thyroid malignant context.

It has been previously shown in PTCs that NIS expression was able to be induced, at some level, by the MEK inhibitor AZD-6244 (selumetinib) (Ho et al. 2013). In fact, in BCPAP cells (in which the MAPK-pathway is constitutively activated) we observed a relevant increase in NIS levels following treatment of cells with AZD-6244. Notably, this increase was considerably improved by the overexpression of active RAC1 (Fig. 6). Overall, these results support the potential of the stimulation of RAC1 activity in enhancing NIS expression in the malignant thyroid context. 


\section{Discussion}

NIS is responsible for active transport of iodide into thyroid cells. Despite NIS expression being retained in most DTCs, its levels and iodide uptake in malignant lesions are reduced when compared to normal tissue (Lazar et al. 1999, Espadinha et al. 2009). Particularly, in a relevant number of metastatic differentiated thyroid cancers, NIS levels became too low to warrant the use of RAI as an adjuvant therapeutic tool, thereby worsening patients' outcome due to lack of effective therapeutic options. Although TSH-derived signaling is a well-defined key regulator of NIS expression in thyroid tissue, neither the overall intracellular signaling events involved in NIS regulation nor the crosstalk among the various protumorigenic pathways that may impact on NIS expression are fully elucidated. p38-MAPK signaling is one of the cues shown to be involved in TSH/cAMP-mediated activation of NIS expression in thyroid non-transformed FRTL5 cells (Pomerance et al. 2000). Another molecular player, also implicated in the pathway leading to p38MAPK activation, is the small GTPase RAC1 (Pomerance et al. 2000). However, although previously observed in the context of breast carcinoma (Kogai et al. 2012), no direct evidence of the impact of RAC1 activity on NIS expression has been obtained in thyroid cell models. In this study, we investigated for the first time the impact of RAC1 on NIS transcriptional expression in two follicular cell-derived thyroid models, as well as of its tumor-related splice variant, RAC1b. In TSH-responsive non-transformed thyroid cells, overexpression of RAC1 was shown to transcriptionally enhance NIS expression. This effect, however, does not seem to involve p38MAPK signaling since neither RAC1 nor G12V-RAC1 ectopic overexpression was found to stimulate p38-MAPK activity, suggesting that another mechanism underlies RAC1-regulated NIS expression in normal thyroid cells. Nevertheless, we found that RAC1 activity in thyroid cells can be stimulated to some extent by TSH, establishing, for the first time, a direct crosstalk between the TSH and RAC1 pathways. Inhibition of endogenous RAC1 activity, on the other hand, led to downregulation of TSH-induced NIS expression and, consistently, was shown to have a negative impact on TSH-induced iodide uptake. Our data thus support a direct contribution of RAC1 signaling to the upregulation of NIS expression in thyroid cells.

In thyroid cancer, NIS downregulation has been associated with the overactivation of several pathways linked to malignant transformation, namely the $\mathrm{PI} 3 \mathrm{~K} / \mathrm{AKT} / \mathrm{mTOR}$ and the MAPK pathways
(Chakraborty et al. 2012, Liu et al. 2012, Xing et al. 2013, Lakshmanan et al. 2014). Constitutive activation of the MAPK pathway, in particular, has been shown to play an important role in repressing NIS expression (Hou et al. 2010). The usefulness of this discovery was nicely illustrated by results of a trial showing that the inhibitor of the MAPK pathway, AZD-6244 (Selumetinib), elicited a meaningful increase in iodide uptake in a subgroup of patients with RAI-refractory TC (Ho et al. 2013). Nevertheless, the use of MAPK-pathway inhibitors only partly restored NIS expression in several experimental models, suggesting that additional signaling cues may be implicated in NIS repression TC cells. In this study, we have shown that the recovery of NIS expression induced by MAPK pathway inhibition is strongly enhanced by the potentiation of RAC1 activity in a TC cell system.

Conversely, we have also shown that overexpression of RAC1's tumor-related variant, RAC1b, is inversely correlated with NIS transcript levels in DTCs. Moreover, we provide evidence that the endogenous levels of both GTPbound, active RAC1 and NIS transcript are downregulated by ectopic overexpression of RAC1b in both FRTL5 and PCCL3 cells. We have previously shown that RAC1b has an important role in PTC development, promoting apoptosis resistance through NF-kB activation (Faria et al. 2017). In fact, besides its overexpression being significantly correlated with an unfavorable outcome in a subset of DTCs, it was shown to be most prevalent in PTCs harboring the oncogenic BRAFV600E mutation, which drives the constitutive activation of MAPK pathway. The fact that tumors bearing BRAF-activating mutations often have high levels of RAC1b expression (Silva et al. 2013) suggest that RAC1b upregulation can cooperate with MAPK signaling or other cancer-associated pathways, to downregulate NIS in DTCs. This could also, at least partially, explain why MAPK pathway inhibitors seldom restore sufficient NIS expression in RAI-refractory DTC cases.

In line with this reasoning, our findings may prove to have further clinical relevance: first, being associated with reduced NIS expression, the detection of increased RAC1b levels in a DTC may have a predictive potential of RAI refractoriness. Studies with larger cohorts are necessary to ascertain this association; second, downregulation of the splicing event that generates RAC1b from the RAC1 pre-mRNA may prove useful in increasing NIS levels and RAI response in refractory DTCs. While, the ectopic modulation of RAC1 alternative splicing has been challenging to date (Melzer et al. 2019), several efforts are being made in this sense in several other malignancies, thus making plausible its future use in the context of TC. 


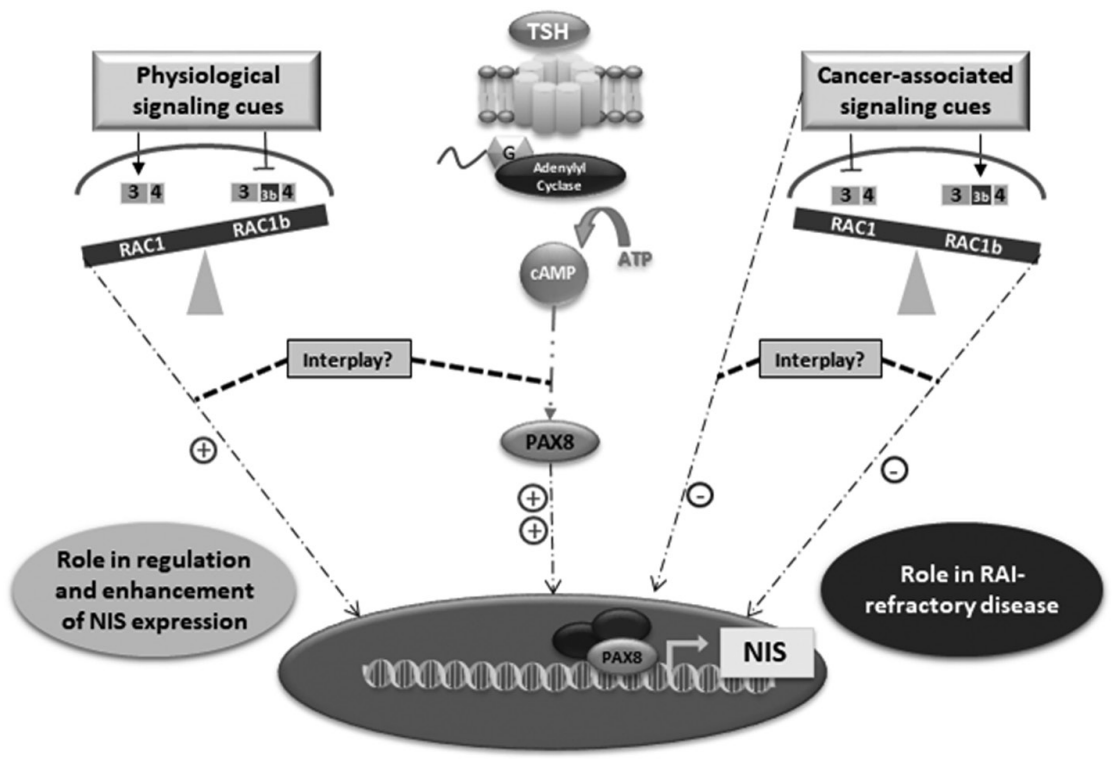

\section{Figure 7}

Antagonistic roles for RAC1 and its tumor-related splice variant RAC $1 \mathrm{~b}$ on NIS expression in thyroid cells: Schematic representation of the antagonistic activities of RAC1 and RAC1b on NIS expression under physiological and pathological conditions (see text for description).
In summary, our findings support the role of RAC1 as a positive modulator of NIS expression in thyroid systems. Under physiological conditions, despite TSH-derived signaling being the key regulator of NIS expression in thyroid tissue, other signaling pathways may have an impact in modulating the extent and effectiveness of this process. Thus, a potential interplay between TSH-derived signals and RAC1 activity may occur, to elicit optimal NIS expression. Under pathological conditions, on the other hand, the overactivation of several pathways linked to thyroid malignancy leads to NIS downregulation. Cancer-associated signaling cues can also favor the alternative-splicing switch that generates RAC1b, leading to the overexpression of this tumor-associated isoform (Fig. 7). The upregulation of RAC1b and its antagonism of RAC1 signaling may thus be one of the mechanisms contributing to the low levels of NIS expression observed in some subgroups of DTCs.

\section{Supplementary data}

This is linked to the online version of the paper at https://doi.org/10.1530/ JME-19-0195.

\section{Declaration of interest}

The authors declare that there is no conflict of interest that could be perceived as prejudicing the impartiality of the research reported.

\section{Funding}

The authors acknowledge the support from grants PTDC/ BIAMOL/31787/2017 (from FTC, Portugal) and LimbertSPEDM/ Genzyme-2015 (from SPEDM/Genzyme, Portugal). M F is recipient of FCT fellowship PD/BD/114388/2016.

(C) 2019 Society for Endocrinology Published by Bioscientifica Ltd. Printed in Great Britain

\section{References}

Barros P, Jordan P \& Matos P 2009 Rac1 signaling modulates BCL-6mediated repression of gene transcription. Molecular and Cellular Biology 29 4156-4166. (https://doi.org/10.1128/MCB.01813-08)

Castro MR, Bergert ER, Goellner JR, Hay ID \& Morris JC 2001 Immunohistochemical analysis of sodium iodide symporter expression in metastatic differentiated thyroid cancer: correlation with radioiodine uptake. Journal of Clinical Endocrinology and Metabolism 86 5627-5632. (https://doi.org/10.1210/ jcem.86.11.8048)

Chakraborty A, Narkar A, Mukhopadhyaya R, Kane S, D'Cruz A \& Rajan MGR 2012 BRAF V600E mutation in papillary thyroid carcinoma: significant association with node metastases and extra thyroidal invasion. Endocrine Pathology 23 83-93. (https://doi. org/10.1007/s12022-011-9184-5)

Cianchetta S, di Bernardo J, Romeo G \& Rhoden KJ 2010 Perchlorate transport and inhibition of the sodium iodide symporter measured with the yellow fluorescent protein variant YFP-H148Q/I152L. Toxicology and Applied Pharmacology 243 372-380. (https://doi org/10.1016/j.taap.2009.12.004)

Cooper DS, Doherty GM, Haugen BR, Kloos RT, Lee SL, Mandel SJ, Mazzaferri EL, McIver B, Sherman SI, Tuttle RM, et al. 2006 Management guidelines for patients with thyroid nodules and differentiated thyroid cancer. Thyroid 16 109-142. (https://doi org/10.1089/thy.2006.16.109)

Dohán O \& Carrasco N 2003 Advances in Na+/I- symporter (NIS) research in the thyroid and beyond. Molecular and Cellular Endocrinology 213 59-70. (https://doi.org/10.1016/j.mce. 2003.10.059)

Dohán O, De la Vieja A, Paroder V, Riedel C, Artani M, Reed M, Ginter CS \& Carrasco N 2003 The sodium/iodide symporter (NIS) characterization, regulation, and medical significance. Endocrine Reviews 24 48-77. (https://doi.org/10.1210/er.2001-0029)

Dralle H, Machens A, Basa J, Fatourechi V, Franceschi S, Hay ID, Nikiforov YE, Pacini F, Pasieka JL \& Sherman SI 2015 Follicular cellderived thyroid cancer. Nature Reviews: Disease Primers 115077. (https://doi.org/10.1038/nrdp.2015.77)

Dumont JE, Maenhaut C, Christophe D \& Roger PP 2016 Thyroid regulatory factors. In Endocrinology: Adult and Pediatric, pp 1297.e81321.e8. Elsevier. (https://doi.org/10.1016/B978-0-323-18907$1.00075-5)$ 
Durante C, Haddy N, Baudin E, Leboulleux S, Hartl D, Travagli JP, Caillou B, Ricard M, Lumbroso JD, De Vathaire F, et al. 2006 Longterm outcome of 444 patients with distant metastases from papillary and follicular thyroid carcinoma: benefits and limits of radioiodine therapy. Journal of Clinical Endocrinology and Metabolism 91 28922899. (https://doi.org/10.1210/jc.2005-2838)

Espadinha C, Santos JR, Sobrinho LG \& Bugalho MJ 2009 Expression of iodine metabolism genes in human thyroid tissues: evidence for age and BRAFV600E mutation dependency. Clinical Endocrinology 70 629635. (https://doi.org/10.1111/j.1365-2265.2008.03376.x)

Faria M, Capinha L, Simões-Pereira J, Bugalho MJ \& Silva AL 2016 Extending the impact of RAC1b overexpression to follicular thyroid carcinomas. International Journal of Endocrinology 20161972367. (https://doi.org/10.1155/2016/1972367)

Faria M, Matos P, Pereira T, Cabrera R, Cardoso BA, Bugalho MJ \& Silva AL 2017 RAC1b overexpression stimulates proliferation and NF-kB-mediated anti-apoptotic signaling in thyroid cancer cells. PLOS ONE 12 e0172689. (https://doi.org/10.1371/journal. pone.0172689)

Fiegen D, Haeusler LC, Blumenstein L, Herbrand U, Dvorsky R, Vetter IR \& Ahmadian MR 2004 Alternative splicing of Rac1 generates Rac1b, a self-activating GTPase. Journal of Biological Chemistry 279 47434749. (https://doi.org/10.1074/jbc.M310281200)

Galietta LJ, Haggie PM \& Verkman AS 2001 Green fluorescent proteinbased halide indicators with improved chloride and iodide affinities. FEBS Letters 499 220-224. (https://doi.org/10.1016/s00145793(01)02561-3)

Heasman SJ \& Ridley AJ 2008 Mammalian Rho GTPases: new insights into their functions from in vivo studies. Nature Reviews: Molecular Cell Biology 9 690-701. (https://doi.org/10.1038/nrm2476)

Ho AL, Grewal RK, Leboeuf R, Sherman EJ, Pfister DG, Deandreis D, Pentlow KS, Zanzonico PB, Haque S, Gavane S, et al. 2013 Selumetinib-enhanced radioiodine uptake in advanced thyroid cancer. New England Journal of Medicine 368 623-632. (https://doi. org/10.1056/NEJMoa1209288)

Hou P, Bojdani E \& Xing M 2010 Induction of thyroid gene expression and radioiodine uptake in thyroid cancer cells by targeting major signaling pathways. Journal of Clinical Endocrinology and Metabolism 95 820-828. (https://doi.org/10.1210/jc.2009-1888)

Jordan P, Brazåo R, Boavida MG, Gespach C \& Chastre E 1999 Cloning of a novel human Rac1b splice variant with increased expression in colorectal tumors. Oncogene 18 6835-6839. (https://doi.org/10.1038/ sj.onc.1203233)

Kogai T \& Brent GA 2009 Regulation and enhancement of endogenous sodium iodide symporter expression. In Comprehensive Handbook of Iodine, pp 221-230. Elsevier. (https://doi.org/10.1016/B978-0-12374135-6.00023-6)

Kogai T \& Brent GA 2012 The sodium iodide symporter (NIS): regulation and approaches to targeting for cancer therapeutics. Pharmacology and Therapeutics 135 355-370. (https://doi.org/10.1016/j. pharmthera.2012.06.007)

Kogai T, Endo T, Saito T, Miyazaki A, Kawaguchi A \& Onaya T 1997 Regulation by thyroid-stimulating hormone of sodium/iodide symporter gene expression and protein levels in FRTL-5 cells. Endocrinology 138 2227-2232. (https://doi.org/10.1210/ endo.138.6.5189)

Kogai T, Liu YY, Mody K, Shamsian DV \& Brent GA 2012 Regulation of sodium iodide symporter gene expression by Rac1/p38 $\beta$ mitogenactivated protein kinase signaling pathway in MCF-7 breast cancer cells. Journal of Biological Chemistry 287 3292-3300. (https://doi. org/10.1074/jbc.M111.315523)

Lakshmanan A, Scarberry D, Shen DH \& Jhiang SM 2014 Modulation of sodium iodide symporter in thyroid cancer. Hormones and Cancer 5 363-373. (https://doi.org/10.1007/s12672-014-0203-0)

Lazar V, Bidart JM, Caillou B, Mahé C, Lacroix L, Filetti S \& Schlumberger M 1999 Expression of the $\mathrm{Na}+/ \mathrm{I}-$ symporter gene in human thyroid tumors: a comparison study with other thyroidspecific genes. Journal of Clinical Endocrinology and Metabolism $\mathbf{8 4}$ 3228-3234. (https://doi.org/10.1210/jcem.84.9.5996)

Li B \& Dewey CN 2011 RSEM: accurate transcript quantification from RNA-Seq data with or without a reference genome. $B M C$ Bioinformatics 12 323. (https://doi.org/10.1186/1471-2105-12-323)

Liu YY, Zhang X, Ringel MD \& Jhiang SM 2012 Modulation of sodium iodide symporter expression and function by LY294002, Akti-1/2 and rapamycin in thyroid cells. Endocrine-Related Cancer 19 291-304. (https://doi.org/10.1530/ERC-11-0288)

Loureiro CA, Matos AM, Dias-Alves Â, Pereira JF, Uliyakina I, Barros P, Amaral MD \& Matos P 2015 A molecular switch in the scaffold NHERF1 enables misfolded CFTR to evade the peripheral quality control checkpoint. Science Signaling 8 ra48. (https://doi.org/10.1126/ scisignal.aaa1580)

Matos P \& Jordan P 2005 Expression of Rac1b stimulates NF-kappaBmediated cell survival and G1/S progression. Experimental Cell Research 305 292-299. (https://doi.org/10.1016/j.yexcr.2004.12.029)

Matos P \& Jordan P 2006 Rac1, but not Rac1B, stimulates RelB-mediated gene transcription in colorectal cancer cells. Journal of Biological Chemistry 281 13724-13732. (https://doi.org/10.1074/jbc. M513243200)

Matos P, Collard JG \& Jordan P 2003 Tumor-related alternatively spliced Rac1b is not regulated by Rho-GDP dissociation inhibitors and exhibits selective downstream signaling. Journal of Biological Chemistry 278 50442-50448. (https://doi.org/10.1074/jbc. M308215200)

Matos P, Oliveira C, Velho S, Gonçalves V, da Costa LT, Moyer MP, Seruca R \& Jordan P 2008 B-Raf(V600E) cooperates with alternative spliced Rac1b to sustain colorectal cancer cell survival. Gastroenterology 135 899-906. (https://doi.org/10.1053/j. gastro.2008.05.052)

Matos AM, Gomes-Duarte A, Faria M, Barros P, Jordan P, Amaral MD \& Matos P 2018 Prolonged co-treatment with HGF sustains epithelial integrity and improves pharmacological rescue of Phe508del-CFTR. Scientific Reports 8 13026. (https://doi.org/10.1038/s41598-018-31514-2)

Mehner C, Miller E, Nassar A, Bamlet WR, Radisky ES \& Radisky DC 2015 Tumor cell expression of MMP3 as a prognostic factor for poor survival in pancreatic, pulmonary, and mammary carcinoma. Genes and Cancer 6 480-489. (https://doi.org/10.18632/genesandcancer.90)

Melzer C, Hass R, Lehnert H \& Ungefroren H 2019 RAC1B: a Rho GTPase with versatile functions in malignant transformation and tumor progression. Cells 8 21. (https://doi.org/10.3390/cells8010021)

Pellegriti G, Frasca F, Regalbuto C, Squatrito S \& Vigneri R 2013 Worldwide increasing incidence of thyroid cancer: update on epidemiology and risk factors. Journal of Cancer Epidemiology 2013 965212. (https://doi.org/10.1155/2013/965212)

Pfaffl MW 2001 A new mathematical model for relative quantification in real-time RT-PCR. Nucleic Acids Research 29 e45. (https://doi. org/10.1093/nar/29.9.e45)

Pomerance M, Abdullah HB, Kamerji S, Correze C \& Blondeau JP 2000 Thyroid-stimulating hormone and cyclic AMP activate p38 mitogenactivated protein kinase cascade. Involvement of protein kinase A, rac1, and reactive oxygen species. Journal of Biological Chemistry 275 40539-40546. (https://doi.org/10.1074/jbc.M002097200)

Radisky DC, Levy DD, Littlepage LE, Liu H, Nelson CM, Fata JE, Leake D, Godden EL, Albertson DG, Nieto MA, et al. 2005 Rac1b and reactive oxygen species mediate MMP-3-induced EMT and genomic instability. Nature 436 123-127. (https://doi.org/10.1038/ nature03688)

Ravera S, Reyna-Neyra A, Ferrandino G, Amzel LM \& Carrasco N 2017 The sodium/iodide symporter (NIS): molecular physiology and preclinical and clinical applications. Annual Review of Physiology $\mathbf{7 9}$ 261-289. (https://doi.org/10.1146/annurev-physiol-022516-034125)

Rhoden KJ, Cianchetta S, Duchi S \& Romeo G 2008 Fluorescence quantitation of thyrocyte iodide accumulation with the yellow 
fluorescent protein variant YFP-H148Q/I152L. Analytical Biochemistry 373 239-246. (https://doi.org/10.1016/j.ab.2007.10.020)

Rhoden KJ, Cianchetta S, Stivani V, Portulano C, Galietta LJV \& Romeo G 2007 Cell-based imaging of sodium iodide symporter activity with the yellow fluorescent protein variant YFP-H148Q/ I152L. American Journal of Physiology: Cell Physiology 292 C814-C823. (https://doi.org/10.1152/ajpcell.00291.2006)

Romei C, Ciampi R, Faviana P, Agate L, Molinaro E, Bottici V, Basolo F, Miccoli P, Pacini F, Pinchera A, et al. 2008 BRAFV600E mutation, but not RET/PTC rearrangements, is correlated with a lower expression of both thyroperoxidase and sodium iodide symporter genes in papillary thyroid cancer. Endocrine-Related Cancer 15 511-520. (https://doi.org/10.1677/ERC-07-0130)

Schnelzer A, Prechtel D, Knaus U, Dehne K, Gerhard M, Graeff H, Harbeck N, Schmitt M \& Lengyel E 2000 Rac1 in human breast cancer: overexpression, mutation analysis, and characterization of a new isoform, Rac1b. Oncogene 19 3013-3020. (https://doi. org/10.1038/sj.onc.1203621)

Silva AL, Carmo F \& Bugalho MJ 2013 RAC1b overexpression in papillary thyroid carcinoma: a role to unravel. European Journal of Endocrinology 168 795-804. (https://doi.org/10.1530/EJE-120960)

Spitzweg C, Bible KC, Hofbauer LC \& Morris JC 2014 Advanced radioiodine-refractory differentiated thyroid cancer: the sodium iodide symporter and other emerging therapeutic targets. Lancet: Diabetes and Endocrinology 2 830-842. (https://doi.org/10.1016/ S2213-8587(14)70051-8)

Stallings-Mann ML, Waldmann J, Zhang Y, Miller E, Gauthier ML, Visscher DW, Downey GP, Radisky ES, Fields AP \& Radisky DC 2012 Matrix metalloproteinase induction of Rac1b, a key effector of lung cancer progression. Science Translational Medicine 4 142ra95. (https:// doi.org/10.1126/scitranslmed.3004062)

Sun W, Duan T, Ye P, Chen K, Zhang G, Lai M \& Zhang H 2018 TSVdb: a web-tool for TCGA splicing variants analysis. BMC Genomics 19 405. (https://doi.org/10.1186/s12864-018-4775-x)

Taki K, Kogai T, Kanamoto Y, Hershman JM \& Brent GA 2002 A thyroidspecific far-upstream enhancer in the human sodium/iodide symporter gene requires Pax- 8 binding and cyclic adenosine 3',5'-monophosphate response element-like sequence binding proteins for full activity and is differentially regulated in normal and thyroid cancer cells. Molecular Endocrinology 16 2266-2282. (https:// doi.org/10.1210/me.2002-0109)

Trapasso F, Iuliano R, Chiefari E, Arturi F, Stella A, Filetti S, Fusco A \& Russo D 1999 Iodide symporter gene expression in normal and transformed rat thyroid cells. European Journal of Endocrinology 140 447-451. (https://doi.org/10.1530/eje.0.1400447)

Wapnir IL, van de Rijn M, Nowels K, Amenta PS, Walton K, Montgomery K, Greco RS, Dohán O \& Carrasco N 2003 Immunohistochemical profile of the sodium/iodide symporter in thyroid, breast, and other carcinomas using high density tissue microarrays and conventional sections. Journal of Clinical Endocrinology and Metabolism 88 1880-1888. (https://doi. org/10.1210/jc.2002-021544)

Xing M, Haugen BR \& Schlumberger M 2013 Progress in molecularbased management of differentiated thyroid cancer. Lancet $\mathbf{3 8 1}$ 1058-1069. (https://doi.org/10.1016/S0140-6736(13)60109-9)

Zhou C, Licciulli S, Avila JL, Cho M, Troutman S, Jiang P, Kossenkov AV, Showe LC, Liu Q, Vachani A, et al. 2013 The Rac1 splice form Rac1b promotes K-ras-induced lung tumorigenesis. Oncogene 32 903-909. (https://doi.org/10.1038/onc.2012.99)

Received in final form 8 September 2019

Accepted 7 October 2019

Accepted Preprint published online 7 October 2019
(C) 2019 Society for Endocrinology Published by Bioscientifica Ltd. Printed in Great Britain 